\title{
Theoretical Studies on the Structure and Acidity of Meldrum's Acid and Related Compounds
}

\author{
Ikchoon Lee, In Suk Han, Chang Kon Kim, and Hai Whang Lee \\ Deparment of Chemistry, Inha Cniversity, Inchon 402-751, Korea \\ Received March 10, 2003
}

\begin{abstract}
The structures and gas-phase ionization energies ( $\Delta G^{\circ}$ ) of Meldrum's acid (I) and related cyclic (II-VI) and acyclic compounds (VII-IX) are investigated theoretically at the MP2/6-31+G*. B3LYP/6-31+G*. B3LYP/6$311+\mathrm{G}^{* *}, \mathrm{~B} 3 \mathrm{LYP} / 6-311+\mathrm{G}(3 \mathrm{df} .2 \mathrm{p})$ and $\mathrm{G} 3(+)(\mathrm{MP} 2)$ levels. Conformations of three neutral cyclic series vary gradually from boat (Meldrum's acid, I). to twisted chair (I) and to chair (III) as the methylene group is substituted for the ether oxygen successively. The preferred boat form of $I$ can be ascribed to the two strong $n_{1}$ $\rightarrow \sigma_{0}$ antiperiplanar vicinal charge transfer interactions and electrostatic attraction between negatively charged $\mathrm{C}^{\mathrm{J}}$ and positively charged $\mathrm{C}^{4}$ at the opposite end of the boat. All the deprotonated anionic forms have half-chair forms due to the two strong $n \rightarrow \pi_{i=c ;}$ vicinal charge transfer interactions. The dipole-dipole interaction theory cannot account for the higher acidity of Meldrum's acid (I) than dimedone (III). The origin of the anomalously high acidity of $\mathbf{I}$ is the strong increase in the vicinal charge transfer $\left(\mathrm{k} \rightarrow \pi_{c}-0\right)$ and 1.4attrative electrostatic interactions $\left(\mathrm{C}^{\mathrm{l}} \leftrightarrow \mathrm{C}^{\dagger}\right)$ in the ionization $\left(\mathbf{I} \rightarrow \mathbf{I}^{-}+\mathrm{H}^{-}\right)$. In the acyclic series (VII-IX) the positively charged end atom. $C^{\dagger}$. is absent and the attractive electrostatic stabilization $\left(C^{l} \leftrightarrow C^{4}\right)$ is missing in the anionic form so that the acidities are much less than the corresponding cyclic series.
\end{abstract}

Key Words : Meldnun's acid. MO theoretical study. Charge transfer. $G 3(+)(M P 2)$. Acidity

\section{Introduction}

The acidity of Meldrum's acid. ${ }^{1} \mathbf{I}$. in aqueous solution $\left(\mathrm{p} K_{\mathrm{a}}=4.83-4.93\right)$ is comparable to that of acetic acid $\left(\mathrm{p} K_{\mathrm{a}}=\right.$ 4.75 ) and hence its structure has been wrongly assigned earlier as the $\beta$-lactone of $\beta$-hy'droxy isopropy'lmalonic acid. ${ }^{1}$ However. Davidson and Bernhard ${ }^{3}$ have reported that the structure of $\mathrm{I}$ is the bislactone of 2.2-dimethyl-1.3-dioxane4.6-dione. and Pfluger and Boyle $\mathrm{e}^{+}$have also shown its conformation to be a boat at least for the crystal. The relatively high acidity of $\mathbf{I}$ has been. therefore. attributed to acidic hydrogens bonded to a carbon existing between the two carbonyl groups. The acidity of $\mathbf{I}$ is anomalously higher than those of all other $\alpha$-carbonyl carbon acids. For example. the $\mathrm{p} K_{\text {a }}$ of $\mathrm{I}$ in DMSO is $7.32^{5}$ but those of dimedone. III. and dimethyl malonate, VII. corresponding to the cyclic and acyclic diketone analogues are 15.87 and 11.16 , respectively. Therefore the Meldrum's acid has attracted considerable attention due to its unusually high acidity.

Recently. Arnett and Harrelson ${ }^{6}$ have proposed that the high acidity of I relative to III or VII is resulted from the restricted rotation around ester bonds in the six-membered ring of $\mathbf{I}$ with a bislactone structure, since the acidities are rapidly decreased on going from 6-menbered to 10 membered ring until 13-membered ring has the same $\mathrm{p} K_{\mathrm{a}}$ as VII. On the other hand, Wang and Houk $^{7}$ have suggested theoretically that the high acidity of $\mathbf{I}$ is originated from the differences in steric and electrostatic (dipole-dipole) repul-

*Corresponding author. Fax: +82-32-865-4855; e-mail: ilee inha.ac.ks sions between $E$ - and $Z$ - ester conformers of neutral and deprotonated anionic molecules using the model compound. methyl acetate. Similarly. Wiberg and Laidig ${ }^{8}$ have shown theoretically that the unusual acidity of I having a bis $(E)$ ester conformation can be accounted for by the difference in acidity between $Z$ - and $E$ - rotamers of methyl acetate Recently, however. Gao and coworkers ${ }^{9}$ pointed out that an additive effect due to the two $E$ esters in the dilactone sistem is not responsible for the high acidity of Meldrum's acid. They have also shown that solvent effects are rather small. and the preferential stabilization of the enolate anion due to anomeric effects is an important factor contributing to the high acidity.

Nevertheless. several questions as to the origin of the unusually high acidity of I still remain: (i) it is not clear why I prefers to have a boat molecular conformation. (ii) it is doubtful that the boat conformation itself and 1.4-steric interaction in the boat conformation of $\mathbf{I}$ are not really relevant to the high acidity. although the possibility of a steric compression effect on the acidity was dismissed in earlier works, ${ }^{6}$ and (iii) it is questionable that cyclization has no other significant effects than the unfavorable bis $(E)$ ester conformation in I as compared to III and acyclic cognates.

In this work we performed systematic investigations on the gas-phase ionization processes of various cyclic. eq. (1). and acyclic diketone analogues, eq. (2), theoretically using the density functional theory (DFT) and $a b$ initio methods in order to elucidate more thoroughly the origin of the unusually high acidity of the Meldrum's acid. 
<smiles>[R]C1([R])[Y]C(=O)C([AlH])([TlH])C(=O)[Y]1</smiles><smiles>[R]C1([R])[Y]C(=O)C=CC1=O</smiles>

Cyclic series:

$\mathrm{R}=\mathrm{CH}_{3} \quad \mathrm{I}: \mathrm{Y}=\mathrm{Y}^{\prime}=\mathrm{O}($ Meldrum s acid $)$

I : $\mathrm{Y}=\mathrm{O}, \mathrm{Y}^{*}=\mathrm{CH}_{2}\left(2,2\right.$-dinnethy $1-(4 \mathrm{H})-\mathrm{p}_{\mathrm{r}}^{\mathrm{r}}$ ran1-4,6-dione $)$

III : $\mathrm{Y}=\mathrm{Y}^{\prime}=\mathrm{CH}_{2}$ (dinedone)

$\mathrm{R}=\mathrm{H}$

IV : $Y=Y=O(1,3$-diosane- 4,6 -dione $)$

$V: Y=O, Y^{\prime}=\mathrm{CH}_{2}$ (dilyydro-pyrant-2,4-dione)

VI : $\mathrm{Y}=\mathrm{Y}^{:}=\mathrm{CH}_{2}(1,3$-cyclohexadione $)$

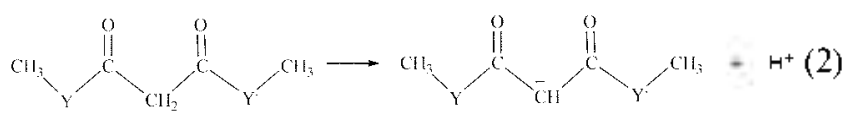

\section{Acyclic series:}

VII : $\mathrm{Y}=\mathrm{Y}^{\prime}=\mathrm{O}$ (dimethyl malonate)

VII : $\mathrm{Y}=\mathrm{CH}_{2}$ and $\mathrm{Y}^{\prime}=\mathrm{O}$ (3-oxo-pentanoic acid methyl ester)

IX : $Y=Y^{*}=\mathrm{CH}_{2}$ (heptane-3,5-dione)

\section{Calculations}

The Gaussian-98 program package ${ }^{10}$ with standard Pople type basis sets was used throughout. All the neutral and enolate species in eqs. (1) and (2) were fully optimized without any symmetry constraints and were verified by the vibrational frequency calculations with the B3LYP/6-
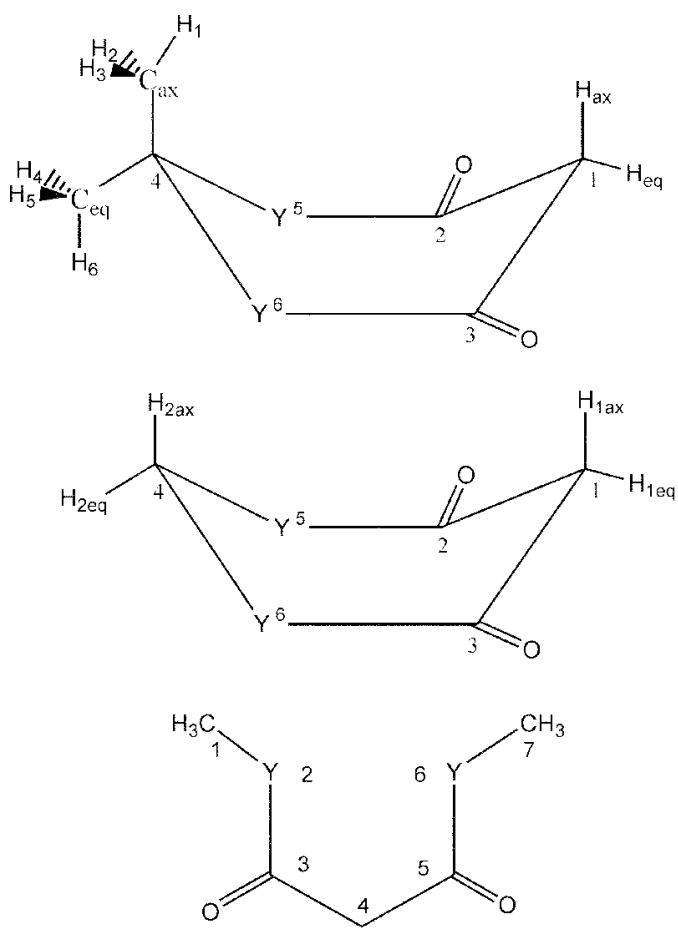

$\mathrm{Y}=\mathrm{CH}_{2}$ or $\mathrm{O}$

Scheme 1
$31+\mathrm{G}^{*} . \mathrm{B} 3 \mathrm{LYP} / 6-311+\mathrm{G}^{* *}$ and $\mathrm{MP} 2 / 6-31+\mathrm{G}^{*}$ basis set. ${ }^{11}$ To improve accuracy of the energetics. fully optimized calculations were carried out at the B3LYP/6-311++G (3df.2p) level of theory with vibrational frequency calculations at the B3LYP $/ 6-311+\mathrm{G}^{* *}$ level. In addition. $\mathrm{G} 3(+)(\mathrm{MP} 2)^{12}$ calculations using the optimized structures and thermody'namic parameters at MP2/6-31+ $\mathrm{G}^{*}$ level were performed for the cyclic compounds. The positional charge densities ${ }^{13 e . t}$ and the second-order charge transfer energies are calculated by using the natural bond orbital (NBO) method ${ }^{13}$ implemented in the Gaussian-98 program. The heavy atom numberings of cyclic and acyclic species are presented in Scheme 1. The free energies of ionization at 298K $\left(\Delta G^{\circ}\right)$ were obtained by $\Delta G^{\circ}=G\left(\mathrm{~A}^{-}\right)+G\left(\mathrm{H}^{+}\right)-$ $G(\mathrm{AH})$ with $G\left(\mathrm{H}^{-}\right)$value of $-6.28 \mathrm{kcal} \mathrm{mol}^{-1} .{ }^{14}$

\section{Results and Discussion}

Structures. The optimized structures of cyclic neutral (IVI) and their deprotonated anionic forms $\left(\mathbf{I}^{-}-\mathbf{V I}^{-}\right)$vary little depending on the theoretical levels (B3LYP/6-31+ $\mathrm{G}^{*}$. B3LYP/6-311+G** and MP2/6-31+G*) employed. The structures of I-III $\left(\mathrm{R}=\mathrm{CH}_{3}\right)$ at the B3LYP/6-311+G** level are shown in Figure 1. Interestingly. conformations of the three neutral series vary gradually from boat for $\mathbf{I}$, through twisted chair for II, to chair for III as the ether oxygens ( $\mathrm{Y}^{5}$ $=Y^{6}=0$ ) are replaced successively by a methylene group in the ring skeleton. In contrast. all the anionic forms $\left(\mathbf{I}^{-}-\mathrm{III}^{-}\right)$ have half-chair conformation.

The structure of $I$ with boat confomation is in good agreement with the experimental results of dipole moment
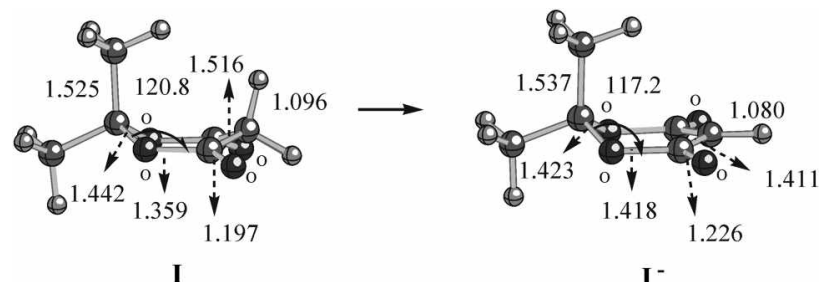

$\mathbf{I}^{-}$
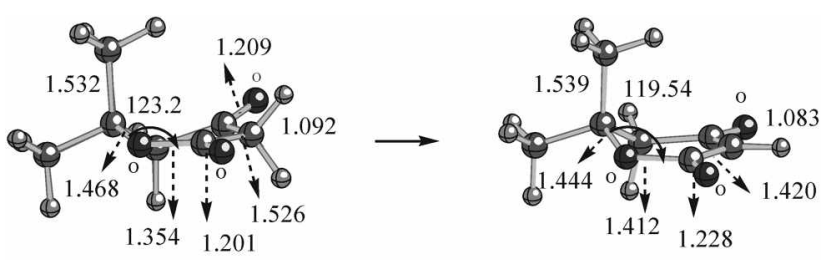

II

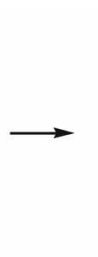

II $^{-}$

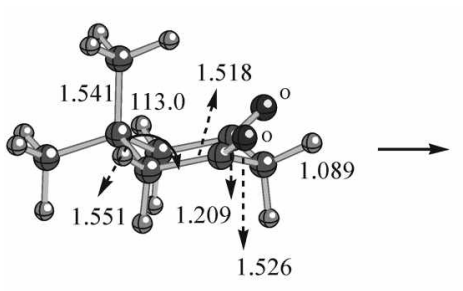

III

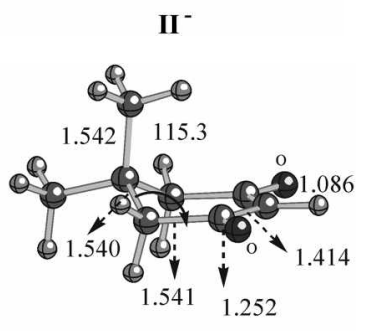

III-

Figure 1. The optimized structures of cyclic species with $\mathrm{R}=\mathrm{CH}_{3}$. I-II, at B3LYP/6-311+G** level. 


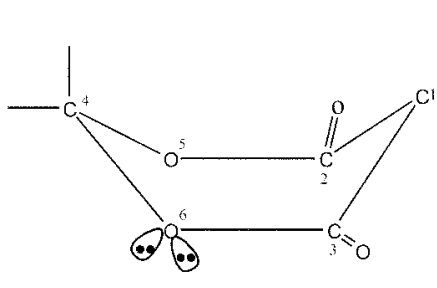

I (boat)

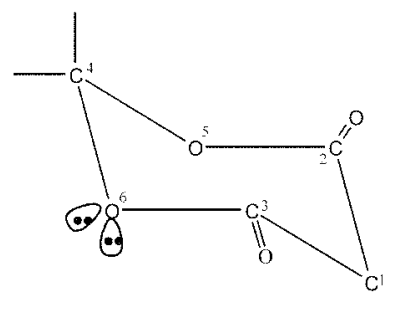

I (chair)
Scheme 2

measurements. ${ }^{15}$ NMR studies ${ }^{16}$ and X-ray structural determination. ${ }^{4}$ Our attempts to obtain optimized structure of I with chair confomation failed at all theoretical levels employed

Why does I prefer to have a boat conformation? According to our analy sis there are at least two factors which are in favor of the boat fom: (i) $n_{0} \rightarrow \sigma_{\mathrm{C}}^{*} \triangle_{-}$interactions. In the boat form the lone pairs on ether oxygens (e.g. $\mathrm{O}^{6}$ ) are oriented antiperiplanar to the $\mathrm{C}-\mathrm{C}\left(\mathrm{C}^{3}-\mathrm{C}^{3}\right)$ bonds while in the chair form they are synperiplanar (Scheme 2). It is well known that antiperiplanar $\mathrm{n} \rightarrow \sigma^{*}\left(\mathrm{n}_{\mathrm{o}} \rightarrow \sigma_{\mathrm{c}^{1} \mathrm{c}^{2}}\right.$ and $\mathrm{n}_{\mathrm{O}} \rightarrow \sigma_{\mathrm{C}^{1}-\mathrm{C}^{3}}$ ) vicinal charge transfer interactions are much stronger (and hence much more stabilizing) than the corresponding synperiplanar interactions. ${ }^{13.17}$ Our natural bond orbital $(\mathrm{NBO})$ analy ses ${ }^{13}$ show that $\mathbf{I}$ is stabilized by the two $\mathrm{n}_{\mathrm{O}} \rightarrow \sigma_{\mathrm{C}-\mathrm{C}}$ interactions by $13.8 \mathrm{kcal} \mathrm{mol}^{-1}$.

In contrast in the anionic form of $\mathbf{I}$ i.e.. in $\mathrm{I}^{-}$. the value is $9.2 \mathrm{kcal} \mathrm{mol}^{-1}$. Since in $\mathbf{I}^{-}$the lone pair (no) is oriented gauche to the $\sigma_{C}^{*}-c_{-}$orbital this means that in the synperiplanar $\mathrm{n}_{\mathrm{O}} \rightarrow \sigma_{\mathrm{C}-\mathrm{C}}$ interactions the stabilization energy will be smaller than this $\left(9.2 \mathrm{kcal} \mathrm{mol}{ }^{-1}\right)$. Thus the vicinal antiperiplanar arrangements of no and $\sigma_{C-c}^{*}$ are conducive to boat conformation for $\mathbf{I}$. It is to be noted that this $n \rightarrow \sigma^{*}$ vicinal charge transfer stabilization is absent

Table 1. The relevant natural population analysis (NPA) charges (in electronic unit) and electrostatic interaction energies ( $\Delta E_{3,}$ in kcal $\mathrm{mol}^{-1}$ ) for $\mathbf{I}-\mathbf{V I}$ and $\mathbf{I}^{-}-\mathbf{V I} \mathbf{I}^{-}$

\begin{tabular}{|c|c|c|c|c|c|c|}
\hline & \multicolumn{4}{|c|}{ NPA charges } & \multicolumn{2}{|c|}{$\Delta E_{\text {完 }}$} \\
\hline & $\mathrm{C}^{3}$ & $\mathrm{C}^{\prime}+\mathrm{H}_{2}($ or $\mathrm{H})$ & $\mathrm{C}^{+}$ & $\mathrm{C}^{+}+\left(\mathrm{CH}_{3}\right)_{2}$ & (a) & (b) \\
\hline I & -0.610 & -0.080 & 0.579 & 0.694 & -42 & -7 \\
\hline $\mathbf{I}^{-}$ & -0.628 & -0.414 & 0.575 & 0.592 & -44 & -30 \\
\hline II & -0.600 & -0.071 & 0.278 & 0.644 & -19 & -3 \\
\hline II' $^{-}$ & -0.571 & -0.364 & 0.265 & 0.284 & -17 & -12 \\
\hline III & -0.570 & -0.073 & -0.073 & 0.020 & 5 & 0 \\
\hline $\mathrm{II}^{-}$ & -0.514 & -0.314 & -0.094 & -0.072 & 5 & 3 \\
\hline IV & -0.612 & -0.083 & 0.267 & 0.630 & -21 & -7 \\
\hline $\mathbf{I V}^{-}$ & -0.631 & -0.418 & 0.280 & 0.564 & -23 & -30 \\
\hline $\mathbf{V}$ & -0.595 & -0.077 & -0.038 & 0.347 & 3 & $-\hat{3}$ \\
\hline $\mathbf{V}^{-}$ & -0.573 & -0.368 & -0.023 & 0.292 & 2 & -13 \\
\hline VI & -0.571 & -0.075 & -0.381 & 0.099 & 24 & 0 \\
\hline $\mathrm{VI}^{-}$ & -0.514 & -0.317 & -0.384 & 0.006 & 23 & 1 \\
\hline
\end{tabular}

(a) Between atoms $\mathrm{C}^{+}$and $\mathrm{C}^{+}$. (b) Between $\left(\mathrm{C}^{-}-\mathrm{H}_{2}\right)$ and $\mathrm{C}^{-1}-\left(\mathrm{CH}_{2}\right)_{2}$ groups. entirely in III which has a chair form. while there is only one such interaction in $\mathbf{I I}\left(8.0 \mathrm{kcal} \mathrm{mol} \mathrm{m}^{-1}\right)$ which has a twisted chair form. (ii) Electrostatic interactions. The relevant atomic and group charges by the natural population analy sis (NPA) ${ }^{\text {l3e. }}$ are collected in Table 1 . We note that the two outof-plane carbons $\left(\mathrm{C}^{]}\right.$and $\left.\mathrm{C}^{-}\right)$, which are at two opposite ends (Scheme 3), are strongly charged in the boat form of I with negative $\left(\mathrm{q}\left(\mathrm{C}^{+}\right)=-0.610\right)$ and positive $\left(\mathrm{q}\left(\mathrm{C}^{4}\right)=+0.579\right)$ charges. respectively. In the twisted chair (II) the positive charge at $\mathrm{C}^{+}\left(\mathrm{q}\left(\mathrm{C}^{4}\right)=+0.278\right)$ decreases while the chair form of III has negative charge at $\mathrm{C}^{4}\left(\mathrm{q}\left(\mathrm{C}^{4}\right)=-0.073\right)$. The electrostatic interaction energies $\left(\Delta E_{\text {es }}\right)$ between the two atoms. $\mathrm{C}^{\mathrm{l}}$ and $\mathrm{C}^{4}$. decreases from -42 (I) to -19 (II) and to $+5 \mathrm{kcal} \mathrm{mol}^{-1}$ (III). and similarly between the two groups at $\mathrm{C}^{-1}\left(\mathrm{C}^{-}+\mathrm{H}_{2}\right)$ and $\mathrm{C}^{4}\left(\mathrm{C}^{4}+\left(\mathrm{CH}_{3}\right)_{2}\right)$ decreases from $\mathrm{I}(-7 \mathrm{kcal}$ $\left.\mathrm{mol}^{-1}\right)$ down to III $(\sim 0)$. This means that the boat form $(\mathbf{I})$ is electrostatically stabilized whereas there is practically no such stabilization in the chair form of III. In fact there is repulsive interaction between $\mathrm{C}^{3}$ and $\mathrm{C}^{4}$ in III so that the two atoms are located as far as possible forming a chair structure. This is in quite contrast to the strong attractive interaction between the $\mathrm{C}^{\mathrm{l}}$ and $\mathrm{C}^{+}$atoms in the boat fonm of $\mathrm{I}$ in which the two atoms are located at a nearest distance. The twisted chair of II is in between the two extreme forms of I and III.

All the anionic forms. $\mathbf{I}^{-}$-III' ${ }^{-}$, have half chair structure since the anionic charge at $\mathrm{C}^{l}$ is strongly delocalized over

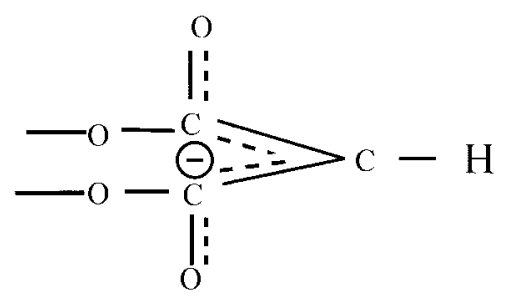

the two carbonyl groups $\left(\mathrm{C}^{2}=\mathrm{O}\right.$ and $\left.\mathrm{C}^{3}=\mathrm{O}\right)$ by strong $\mathrm{n}_{\mathrm{C}} \rightarrow$ $\pi_{C^{\prime}=0}^{*}$ vicinal charge transfer interactions and form a coplanar moiety:

Unfortunately. Gao and coworkers have not included these strong $n_{C} \rightarrow \pi_{C=0}^{*}$ interaction energies in their NBO analy sis of the Meldrum's acid. These $n_{C} \rightarrow \pi_{C=0}$ vicinal charge transfer energies are especially large since the lone pair on $\mathrm{C}^{l}$ is a p type (and hence is at a higher level than other $\mathrm{sp}^{2}$ or $\mathrm{sp}^{3}$ type lone pairs) and the $\pi$ orbital is lower than $\sigma^{*}$ orbitals leading to a narrower energy gap. $\Delta \varepsilon$. in the second - order perturbation energy. ${ }^{13.17} \Delta E^{.0)}{ }_{n \rightarrow \pi^{*}}$ in eq. (3). The stabilization of anionic forms.

$$
\Delta F_{n \rightarrow \pi^{*}}^{(\nu)}=-2\left(F_{n} \pi^{2}\right)^{2} /\left(\varepsilon_{\pi^{*}}-\varepsilon_{n}\right)=-2\left(F_{n \pi^{*}}\right)^{2} / \Delta \varepsilon
$$

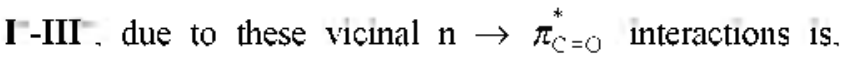
however, the lowest in $\mathrm{I}^{-}$(Table 2).

This is due to elevation of the $\pi_{C=0}^{*}$ level by the vicmal lone pairs on ether oxygen $\left(\mathrm{O}^{5}\right.$ and $\left.\mathrm{O}^{6}\right)$. Thus the $\pi_{\mathrm{C}=0}$ level is the lighest in $\mathrm{I}^{-}\left(\varepsilon_{\pi^{*} C=0}=0.3802\right.$ w 0.3733 and 0.3587 a.u. for the corresponding orbitals in $\mathrm{II}^{-}$and $\mathrm{III}^{-}$ respectively), and hence the $\mathrm{n} \rightarrow \pi^{i} \mathrm{c}=0$ charge transfer energy $\left(\Delta E_{\mathrm{n} \rightarrow \pi^{*}}\right.$ in eq. (3)) is the smallest due to the widest 
Table 2. The vicinal $\mathbf{n}_{C} \rightarrow \pi_{C=0}^{*}$ charge transter energies $\left(-\Delta E_{n \rightarrow \pi^{\prime}}^{\mid 2)}\right)$ in anionic fonns, $\mathbf{I}^{-} \rightarrow \mathbf{V I}^{-}$, in kcal mol $\mathrm{kn}^{-1}$

\begin{tabular}{cccc}
\hline & $\mathbf{I}^{-}$ & $\mathbf{I}^{-}$ & $\mathbf{I I}^{-}$ \\
\hline $\mathrm{C}^{1}-\mathrm{C}^{-}=\mathrm{O}$ & 124.9 & 127.3 & 150.6 \\
$\mathrm{C}^{1}-\mathrm{C}^{\mathbf{3}}=\mathrm{O}$ & 124.9 & 156.1 & 150.6 \\
\hline & $\mathbf{I V}^{-}$ & $\mathbf{V}^{-}$ & $\mathbf{V I}^{-}$ \\
\hline $\mathrm{C}^{1}-\mathrm{C}^{-2}=\mathrm{O}$ & 123.2 & 124.5 & 150.6 \\
$\mathrm{C}^{1}-\mathrm{C}^{3}=\mathrm{O}$ & 123.5 & 155.6 & 150.6 \\
\hline
\end{tabular}

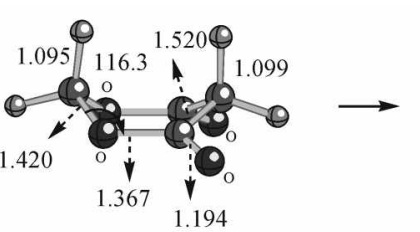

IV

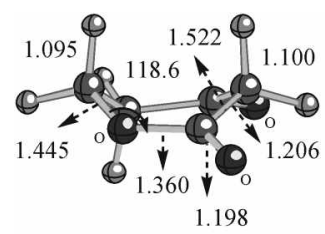

V

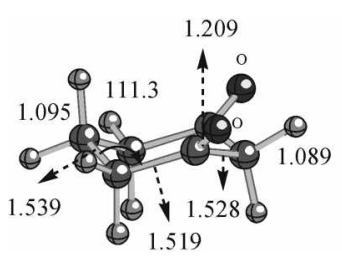

VI

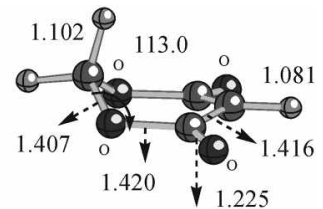

IV $^{-}$

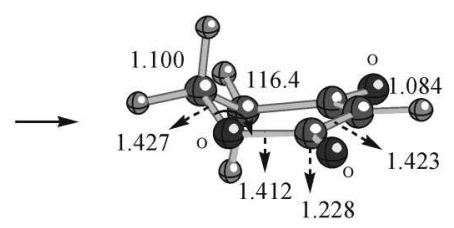

$\mathbf{V}^{-}$

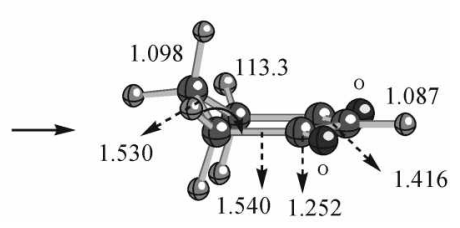

VI $^{-}$
Figure 2. The optimized structures of cyclic species with $\mathrm{R}=\mathrm{H}$, IV-VI, at B3LYP/6-31 1+G** level

energy gap. $\Delta \varepsilon$. Based solely on the charge transfer stabilization. the stability of anionic foms should decrease in the order. $\mathrm{III}^{-}>\mathrm{II}^{-}>\mathrm{I}^{-}$. However, this is misleading since there are stronger electrostatic stabilizations in $\mathrm{I}^{-}$than in $\mathbf{~ I I}^{-}$ and III- $^{-}$as can be seen in Table 1 .

The optimized structures of cyclic neutral (IV-VI) and anionic forms with $\mathrm{R}=\mathrm{H}\left(\mathbf{I V}^{-}-\mathbf{V I}^{-}\right)$at the B3LYP/6$311+\mathrm{G}^{* *}$ level are presented in Figure 2 . The structures of IV-VI are similar to those of their dimethyl analogous. I-III. except that $\mathbf{V}$ has a boat form instead of a twisted chair which was found with II. This indicates simply that either there is some 1-4 steric repulsion in II due to the two bulky
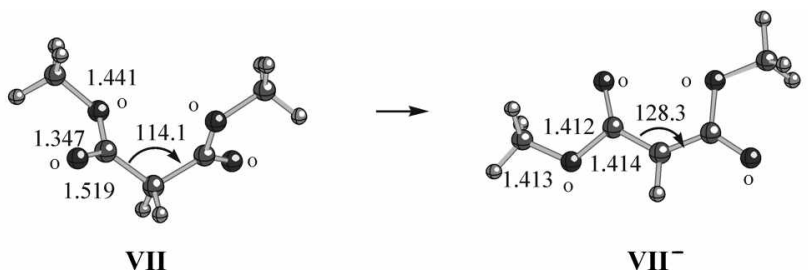

VII $^{-}$
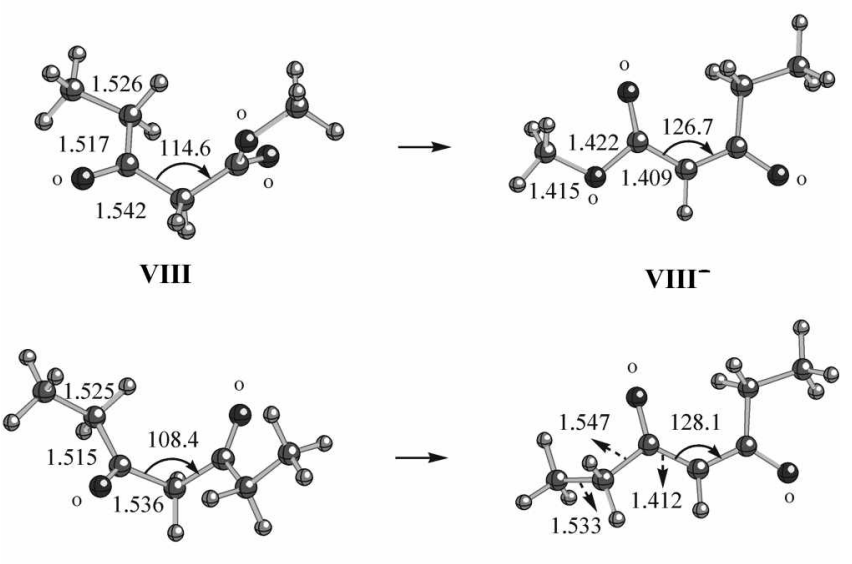

$\mathrm{IX}^{-}$

Figure 3. The optimized structures of acyclic species, VII-IX, at B3LYP/6-31I+G** level.

$\mathrm{CH}_{3}$ groups on $\mathrm{C}^{4}$. or there is stronger 1.4-attraction in $\mathbf{V}$ than in II. In fact. the 1.4-steric attraction (vide infra) enforces shorter interatomic distance between $\mathrm{C}^{l}$ and $\mathrm{C}^{+}$in IV by $0.17 \AA$ than that in $\mathrm{I}$ and as a result torsional angles $\left(\theta^{l}\right.$ in Scheme 3) of the two ends. $C^{l}$ and $C^{4}$. from the molecular base $\left(\mathrm{O}^{5}-\mathrm{C}^{2}-\mathrm{C}^{3}-\mathrm{O}^{6}\right)$ plane in $\mathbf{I V}$ are larger by $4.5^{\circ}$ compared to those in I. This suggests that Meldrum 's acid. $I$, is a cyclic compound with no significant 1.4-steric repulsion so that its relaxation on going from neutral to anionic species does not contribute significantly to the high acidity of $\mathbf{I}$.<smiles></smiles>

['-sisupe<smiles>[R]C(=O)C=C([R])[O-]</smiles>

Sickle-shape $\mathrm{R}=\mathrm{OCH}$, or $\left.\mathrm{CH}_{2} \mathrm{CH}_{1}\right)$

Scheme 4

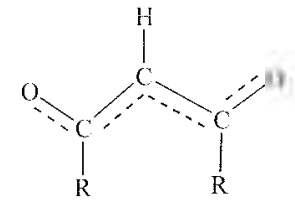

M-Shape

out -of-plane atoms at two ends $\left(\mathrm{C}^{1}\right.$ and $\left.\mathrm{C}^{4}\right)$

$$
\begin{array}{ccc} 
& \theta^{1} & \theta^{2} \\
\text { I : } & 59.2 & 64.2 \\
\text { IV : } & 63.7 & 66.0
\end{array}
$$




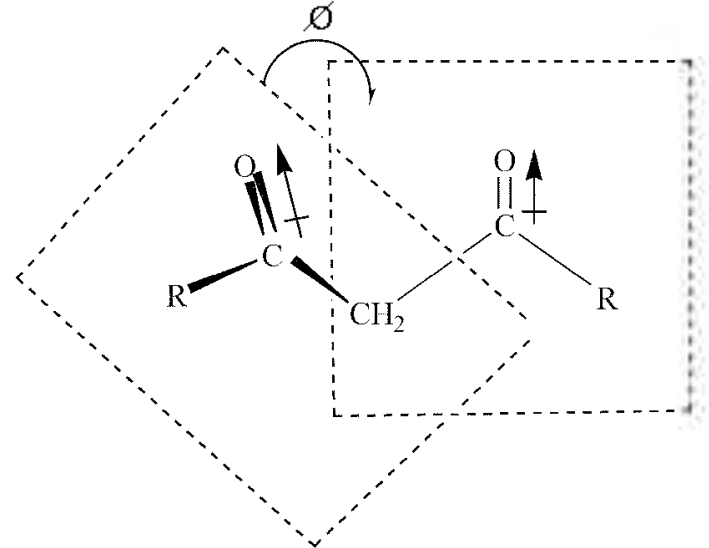

$\left(\mathrm{R}=\mathrm{OCH}_{3}\right.$ or $\left.\mathrm{CH}_{2} \mathrm{C}_{3}\right)$

Scheme 5

Optimized structures of the three acyclic species, VII-IX, at the B3LYP/6-311-G** level are shown in Figure 3. Unlike in cyclic analogues, I-VI, the two carbonyl groups have to be W-shaped ${ }^{18}$ (Scheme 4) within molecular plane.

Due to electrostatic or dipole-dipole repulsion the two carbonyl groups are twisted away each other as shown in Scheme 5. The twist angle $(\phi)$ increases in the order VII $\left(35.3^{\circ}\right)<$ VIII $\left(49.6^{\circ}\right)<$ IX $\left(86.2^{\circ}\right)$. However in the anionic forms, $\mathbf{V I I}^{-}-\mathbf{I X}^{-}$, two carbonyl groups and the anionic center are nearly coplanar due to $\mathrm{n}_{C} \rightarrow \pi_{\left.\mathrm{C}_{-}\right)}^{*}$ vicinal charge transfer interactions with Sickle-shaped conformation in contrast to the $\mathrm{W}$-shaped neutral species. For the charge delocalized anions, three conformations are possible as shown in Scheme 4, and relative preference depends on $\mathrm{R}$ which is $\mathrm{OCH}_{3}$ or $\mathrm{CH}_{2} \mathrm{CH}_{3}$. In the absence of steric repulsion, the $\mathrm{U}$-shaped anion has the strongest electrostatic repulsion and the $W$-shaped anion will be the most stabilized. However the Sickle-shaped anions are favored by ca. $1-5 \mathrm{kcal} \mathrm{mol}^{-1}$ than the $W$-shaped ones in all cases indicating that steric interaction between the two $R$ groups is significant. The stable conformations shown in Figure 3 are determined mainly by the favorable electrostatic interactions

Table 3. The (jibbs free energy changes ( $\Delta C^{\circ}$ in $\mathrm{kcal} \mathrm{mol}^{-1}$ ) for the ionizations of cyclic and acyclic species. I-IX. obtained at various levels of theory

\begin{tabular}{|c|c|c|c|c|c|}
\hline & $\begin{array}{c}M P 2 / \\
6-31-i^{*}\end{array}$ & $\begin{array}{l}1331, Y P: \\
6-31-6 ;\end{array}$ & $\begin{array}{l}1331 . Y P 6- \\
311+6 * *\end{array}$ & $\begin{array}{c}\text { B3I.YPiG- } \\
311+-(3(3)-2 p)\end{array}$ & $\begin{array}{l}(\mathrm{G} 3(+) \\
(\mathrm{MP} 2)\end{array}$ \\
\hline ] & 319.5 & 321.1 & 321.5 & 322.7 & 324.3 \\
\hline II & 323.0 & 323.9 & 324.5 & 325.2 & 327.0 \\
\hline 111 & 324.8 & 324.8 & 325.5 & 325.8 & 328.5 \\
\hline IV & 317.3 & 318.0 & 318.5 & 319.9 & 322.4 \\
\hline$V$ & 322.5 & 322.8 & 323.4 & 324.2 & 326.7 \\
\hline VI & 325.0 & 325.1 & 325.7 & 326.1 & 328.8 \\
\hline VII & 338.4 & 336.6 & 337.0 & 337.0 & \\
\hline VIII & 332.6 & 331.6 & 330.9 & 331.2 & \\
\hline JX & 331.3 & 331.5 & 332.1 & 332.5 & \\
\hline
\end{tabular}

within the molecules since the $n_{0} \rightarrow \pi_{\mathrm{C}-\mathrm{O}}$ vicinal charge transfer stabilization will not differ significantly between many possible conformations.

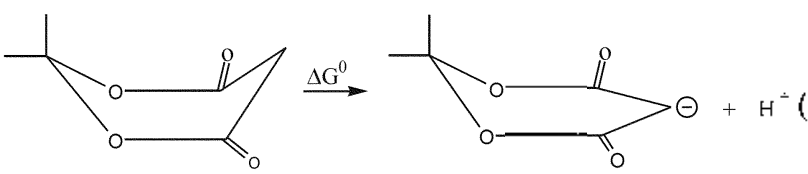

Acidity. The gas-phase ionization energies, $\Delta G^{\circ}$ at $298 \mathrm{~K}$ in eq (4) (for $\mathbf{I} \rightarrow \mathbf{I}^{-}+\mathrm{H}^{-}$), calculated at various levels of theory are summarized in Table 3 . The relative values at the $\mathrm{G} 3(+)(\mathrm{MP} 2)$ and $\mathrm{B} 3 \mathrm{LYP} / 6-3 \mathrm{I} 1+\mathrm{G}(3 \mathrm{df}, 2 \mathrm{p})$ levels are presented in Figure 4 together with the experimentally (in DMSO at $25^{\circ} \mathrm{C}$ ) available values." The $\Delta G^{\circ}$ ' value of Meldrum's acid (I) is lower by 14.3 and $3.1 \mathrm{kcal} \mathrm{mol}^{-1}$ than that of dimethyl malonate (VII) and dimedone (III) at the B3LYP/6-311++G(3df,2p) level, respectively. The former is larger $\left(\delta \Delta G^{(\mathrm{i}} \mathrm{Dj}\left[\mathrm{C}-\delta \Delta G^{\mathrm{a}}{ }_{\mathrm{cxp}}-2.6 \mathrm{kcal} \mathrm{mol}^{-1}\right.\right.$ where $\delta \Delta G^{\mathrm{w})}-$ $\left.\Delta G^{\prime}(\mathbf{V I I})-\Delta G^{\prime \prime}(\mathbf{I})\right)$ but the latter is smaller $\left(\delta \Delta G^{\prime \prime}\right.$ ver $\delta \Delta G_{\mathrm{cxp}}^{\mathrm{n}}--2.2 \mathrm{kcal} \mathrm{mol}{ }^{-1}$ where $\left.\delta \Delta G^{0}-\Delta G^{0}(\mathbf{I I I})-\Delta G^{\circ}(\mathbf{I})\right)$ by cu. $2 \mathrm{kcal} \mathrm{mol}^{-1}$ than the respective experimental values in DMSO. The $G 3(+)(\mathrm{MP} 2)$ result $\left(\delta \Delta G^{\circ}-\Delta G^{\circ}(\mathbf{I I I})-\right.$ $\left.\Delta G^{\mathrm{o}}(\mathbf{I})-4.2 \mathrm{kcal}^{\mathrm{mol}} \mathrm{m}^{-1}\right)$ is in better agreement with the experimental value of $\delta \Delta G^{\circ}-5.2 \mathrm{kcal} \mathrm{mol}^{-1}$ than the DFT value $\left(\delta \Delta G^{\circ}-3.1 \mathrm{kcal} \mathrm{mol}^{-1}\right)$. However, the trends of changes in the $\Delta G^{\circ}$ values $\left(\delta \Delta G^{\circ}\right)$ are all in good accord: (i) The acidity increases ( $\Delta G^{\prime \prime}$ is reduced) greatly by cyclization (VII $\rightarrow$ I, VIII $\rightarrow$ II and IX $\rightarrow$ III) and (ii) the introduction

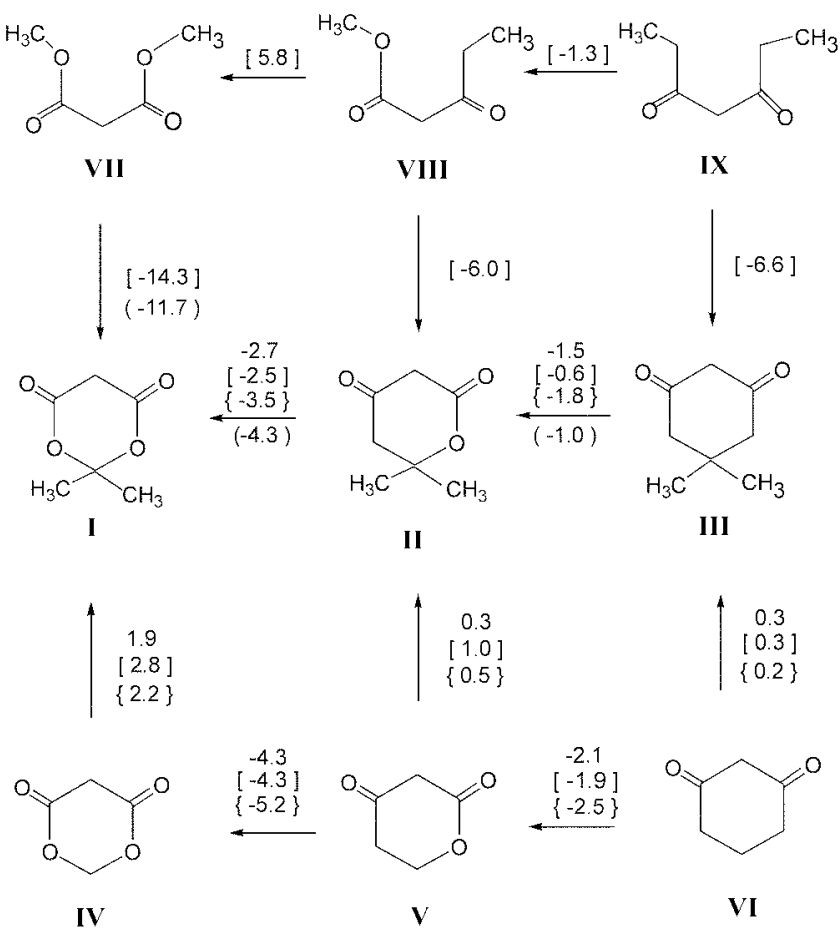

Figure 4. Dilierences in free energics of ionization ( $\triangle G^{\circ}$ al $298 \mathrm{~K}$ ) Lalculated at the $(33(-)(M P 2), B 3 L Y P / 6-311+c(3 d t .2 p)$ [in bracket] and MP2/6-31- $\mathrm{G}^{*}$; in round bracket; levels. Values in parenthesis are experimental results in IMMSO at $25^{\circ} \mathrm{C}$. 
of second ether oxygen (II $\rightarrow$ I) leads to a greater decrease in $\Delta G^{\circ}$ than the first ether oxygen (III $\rightarrow$ II). The disagreements of the theoretical gas-phase $\Delta G^{\circ}$ values with the experimental results in DMSO may arise from solvent effects. It is conceivable that the highly polarized structure of $\mathbf{I}^{-}$relative to $\mathbf{I I I}^{-}$(Table 1) may lead to enhanced stabilization by solvation. which will give a stronger acidity for Meldrum's acid (I) than for dimedone (III) in DMSO. However. this possibility is low since a good correlation of the $\mathrm{p} K_{\text {a }}$ values in DMSO with gas phase values were found..$^{7.11 .19}$ Alternatively. improper accounting of interorbital correlation energy between localized lone pairs on the two neighboring oxygen atoms may be the cause for these discrepancies. The DFT method is known to overestimate electron correlation energy for delocalized systems. underestimate interorbital pair correlation energy between localized lone pairs on the two neighboring atoms. ${ }^{21}$ In the deprotonation of $\mathbf{I}$ (into $\mathbf{I}^{-}+\mathrm{H}^{+}$). electron population of lone pairs on the two ether oxygens increases (charge increases on the ether oxy'gen from -0.575 to -0.635 ). Underestimation of interorbital pair correlation energies between the lone pairs on the two in-plane ether oxygens (Scheme 3) should lead to an unduly high energy for $\mathbf{I}^{-}$so that the $\Delta G^{\circ}$ value will become higher than that would have been obtained if proper accounting had been made. Since there are no ether oxygens in III. no such inadequate accounting of pair correlation energy occurs in the $\Delta G^{\circ}$ value for the deprotonation of III. Thus approximately $2 \mathrm{kcal} \mathrm{mol}^{-1}$ difference in the acidity ( $\delta \Delta G_{\mathrm{DFT}}^{\circ}-\delta \Delta G_{\mathrm{exp}}^{\circ}=3.1-5.3=$ $-2.2 \mathrm{kcal} \mathrm{mol}^{-1}$ ) may have come from this underestimation in the deprotonation of $\mathbf{I}$. On the other hand. the two ether oxygens are twisted away in VII (Scheme 5) but an ether and a carbonyl oxygen approach to a near distance within the

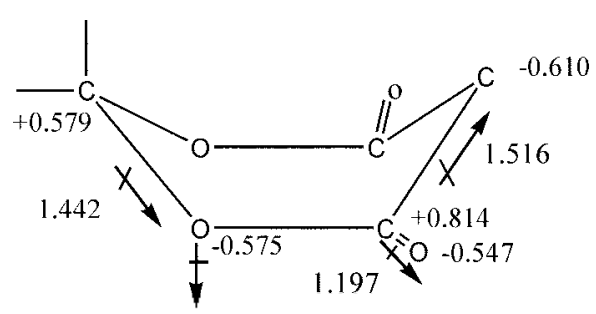

1

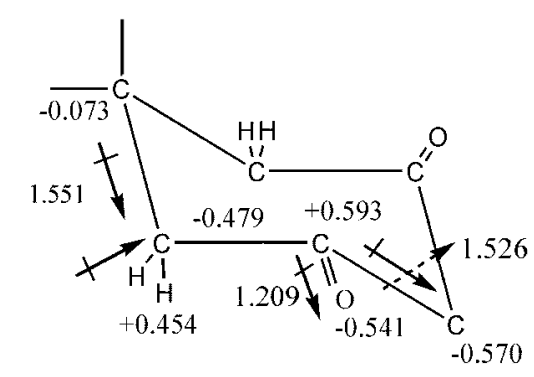

III two coplanar ester groups in $\mathrm{VII}^{-}$(Figure 3). This means that the underestimation of interorbital pair correlation energy will be large in the deprotonation of VII due to a large increase in the interorbital pair interaction from VII to $\mathrm{VII}^{-}$. Consequently, the undue increase in $\Delta G^{\circ}$ will be large for the deprotonation of VII. The relative acidity decrease due to the underestimated interorbital pair correlation energy by the DFT method may be ca. $4.8 \mathrm{kcal} \mathrm{mol}^{-1}$. leading to enhanced acidity difference of $2.6 \mathrm{kcal} \mathrm{mol}^{-1}$ between VII and $\mathbf{I}$ since $\delta \Delta G_{\mathrm{DFT}}^{\circ}-\delta \Delta G_{\mathrm{exF}}^{\circ}=4.8 \mathrm{kcal} \mathrm{mol}^{-1}$ results from $(2.6+2.2) \mathrm{kcal} \mathrm{mol}^{-1}$ where $2.2 \mathrm{kcal} \mathrm{mol}^{-1}$ is the decrease in the acidity of $\mathbf{I}$ due to the underestimated electron correlation. Interestingly, the dimethyl series. I-III. are all less acidic. i.e. $\Delta G^{\circ}$ values are higher, than the corresponding unsubstituted counterparts. IV-VI, e.g.. I is less acidic by $\delta \Delta G^{n}=2.8 \mathrm{kcal} \mathrm{mol}^{-1}$ than $\mathbf{I V}$, (wide infra).

What is the origin of the unusually high acidity of Meldnum's acid. I? We first examine the dipole-dipole interaction theory for explaining the origin of the abnormal acidity of Meldrum's acid. ${ }^{7.82}$ Experimentally. Meldnum's acid (I) was found to be $5.24 \mathrm{kcal} \mathrm{mol}^{-1}$ more acidic than dimedone (III). i.e. deprotonation of III is $5.24 \mathrm{kcal} \mathrm{mol}^{-1}$ more endothermic than deprotonation of $\mathrm{I}$ in DMSO at $25^{\circ} \mathrm{C}$ $\left(\delta \Delta G^{\circ}=5.24 \mathrm{kcal} \mathrm{mol}^{-1}\right)$. The corresponding values in the gas phase obtained in the present work are $\delta \Delta G^{\circ}=5.3$. 3.1 and $4.2 \mathrm{kcal} \mathrm{mol}^{-1}$ at the MP2 $/ 6-31+\mathrm{G}^{*}$. B3LYP $/ 6-31 \mathrm{l}++\mathrm{G}$ (3df.2p) and G3(+)(MP2) level respectively. The MP2 value is in excellent agreement with the experimental result. However. this may be fortuitous since it is well known that the MP2 method overestimates electron correlation energy for the delocalized structure ${ }^{3(t .2) \mathrm{b} .23}$ Since the deprotonated forms $\left(\mathbf{I}^{-}\right.$-III') are strongly delocalized. overestimation of electron correlation for these anionic forms will result in an

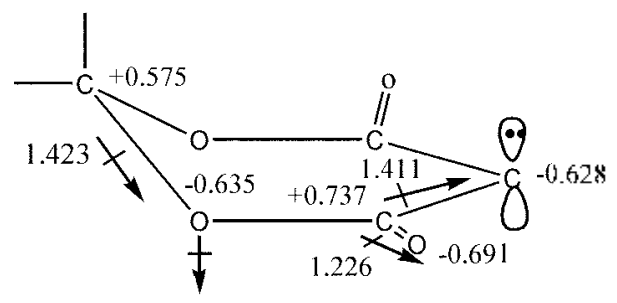

$I^{-}$

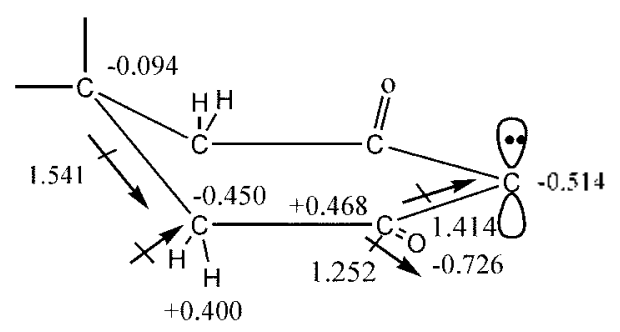

III -

Figure 5. The natural population analysis (NPA) atomic charges (electronic unit) and bond lengths ( $A$ ) with qualitative dipoles component arrows in deprotonation of Meldrum 's $\left(\mathbf{I} \rightarrow \mathbf{I}^{-}\right)$and dimedone $\left(\mathbf{I I} \rightarrow \mathbf{I I}^{-}\right)$. 
enhanced acidity. The overestimation of electron correlation will be greater. naturally for the system with a larger exclusion repulsion involving lone pairs, i.e.. the effect will be greater in $\mathbf{I}^{-}$(with extra lone pairs on the two ether oxygens) than in III $^{-}$(with no ether oxygen). The MP2 acidity difference of $5.3 \mathrm{kcal} \mathrm{mol}^{-1}$ between I and III may therefore be attributed partly to the overestimation of electron correlation energies by the MP2 method. The enhanced acidity due to the overestimation of electron correlation increases thus in the order III $<$ II $<$ I. This trend is evident in Table 3. since the lowest $\Delta G^{\circ}$ value. or the strongest acidity: is obtained by MP2 than by any other method. For example. the $\Delta G^{0}$ value is $319.5 \mathrm{kcal} \mathrm{mol}^{-1}$ for I by MP 2 but this is lower by 1.6 and $4.8 \mathrm{kcal} \mathrm{mol}^{-1}$ than those by $\mathrm{B} 3 \mathrm{LYP} / 6-31+\mathrm{G}^{*}$ and $\mathrm{G} 3(+)(\mathrm{MP} 2)$, respectively.

The G3(+)(MP2) and DFT values are all somewhat smaller ranging from 3.1 to $4.2 \mathrm{kcal} \mathrm{mol}^{-1}$ as the basis sets are varied (Table 3). The DFT (B3LYP) values do not converge to a limiting value as the basis set is increased 3.7 $\left(6-31+\mathrm{G}^{*}\right) \rightarrow 4.0\left(6-311+\mathrm{G}^{* *}\right) \rightarrow 3.1 \mathrm{kcal} \mathrm{mol}^{-1}(6-311++\mathrm{G}$ (3df.2p)). The best value is that $\left(4.2 \mathrm{kcal} \mathrm{mol}^{-1}\right)$ obtained by the G3(+)(MP2) theory, which is an improved method over the G2(MP2) as well as the G2 theory. ${ }^{12}$ Since the composite ab initio method. G3(+)MP2, can often achieve an accuracy of 1-2 kcal mol${ }^{-1}$ in the various energy calculation. ${ }^{12}$ the agreement of our gas- phase (G3(+)(MP2)) value $(4.2 \mathrm{kcal}$ $\mathrm{mol}^{-1}$ ) with the experimental result in DMSO $\left(5.2 \mathrm{kcal} \mathrm{mol}^{-1}\right)$ should be deemed good considering enrors involved in the experimental measurements. ${ }^{56}$

The NPA charges are shown in Figure 5 for atoms involved in the deprotonation of Meldrum's acid $\left(\mathbf{I} \rightarrow \mathbf{I}^{-}\right)$ and dimedone (III $\rightarrow \mathrm{III}^{-}$) with dipole moment components depicted qualitatively by arrows. We note that the boat conformation of $I$ is stabilized by interaction of two out-ofplane dipoles pointing in opposite direction (antiparallel dipoles of $\mathrm{C}^{3} \longrightarrow \mathrm{C}^{1}$ and $\mathrm{O}^{6} \longrightarrow+\mathrm{C}^{4}$ ). In contrast. the corresponding out-of-plane dipoles are pointing in the same direction in III (parallel dipoles of $\mathrm{C}^{3} \longrightarrow \mathrm{C}^{\mathrm{l}}$ and $\mathrm{C}^{+} \longrightarrow \mathrm{C}^{6}$ ) leading to destabilization of the chair conformation of III. These relative stabilities of $\mathbf{I}$ and III based on dipole interactions involving the two out-of-plane end atoms $\left(\mathrm{C}^{l}\right.$ and $\mathrm{C}^{4}$ ) are consistent with the preferred conformations of $\mathbf{I}$ (boat) and III (chair). since the attractive force pull together in I to a shorter distance (boat) while the repulsive force push apart the two ends in III to a farther distance (chair). There are. however. another in-plane pair of dipoles within the base plane composed of the two ester groups $\left(-\mathrm{O}^{6}-\right.$ $\mathrm{C}^{3}(=\mathrm{O})-$ and $\left.-\mathrm{O}^{5}-\mathrm{C}^{2}(=\mathrm{O})-\right)$ in $\mathrm{I}$ and the corresponding groups $\left(-\mathrm{C}^{6} \mathrm{H}_{2}-\mathrm{C}^{3}(=\mathrm{O})-\right.$ and $\left.-\mathrm{C}^{5} \mathrm{H}_{2}-\mathrm{C}^{2}(=\mathrm{O})-\right)$ in III: two in-plane dipoles within the molecular base plane of $\mathbf{I}$. $\mathrm{O}^{6} \longrightarrow \mathrm{n}_{\circ}$ and $\mathrm{C}^{3} \longrightarrow \mathrm{O}$ where $\mathrm{n}_{\circ}$ is the lone pairs on the ether oxygen atom. are parallel (destabilizing) whereas the corresponding pairs in III. $\mathrm{C}^{6} \longrightarrow \mathrm{H}_{2}$ and $\mathrm{C}^{3} \longrightarrow \mathrm{O}$. are antiparallel (stabilizing). In the deprotonation of $\mathbf{I}\left(\rightarrow \mathbf{I}^{-}\right)$and III $\left(\rightarrow\right.$ III $\left.^{-}\right)$. these two sets of in-plane dipoles are not reduced to a similar extent. On the contrary inspection of Figure 5 reveals that the two in-plane dipoles in $\mathbf{I}$ are strengthened in $\mathbf{I}^{-}$. since (i) polarity of the carbonyl group is increased with bond length stretch, and (ii) the negative charge on the ether oxy'gen is increased (and hence a greater occupation of the lone pair orbital. no). In contrast. changes in dipole strength will be small in $\mathbf{~ I I ~} \rightarrow$ III $^{-}$. since polarity of $\mathrm{CH}_{2}$ decreases while that of $\mathrm{C}=\mathrm{O}$ increases. These results indicate that the deprotonation of $\mathbf{I}$ into $\mathbf{I}^{-}$is accompanied by destabilization due to the increased repulsion of the in-plane parallel dipoles. whereas the deprotonation of III into $\mathrm{III}^{-}$ causes little change in the dipole interaction between the inplane antiparallel dipoles. The consequences of this in-plane dipole interaction analysis is that the acidity of III should be greater than that of I since the change of III $\rightarrow$ III $^{-}$is less endothermic than that of $\mathbf{I} \rightarrow \mathbf{I}^{-}$. This conclusion, based solely on the in-plane dipole interactions. is of course absurd and in direct contradiction to the experimental $\left(\delta \Delta G^{\circ}=5.2\right.$ kcal $\mathrm{mol}^{-1}$ ) as well as our gas-phase theoretical $(\mathrm{G} 3(+)(\mathrm{MP} 2))$ result $\left(\delta \Delta G^{\circ}=4.2 \mathrm{kcal} \mathrm{mol}^{-1}\right)$ of the enhanced acidity of $\mathbf{I}$ relative to III. We therefore tum our attention to the analy sis based on the natural bond orbital (NBO) theory. ${ }^{13}$ In the following. we will show based on the NBO analysis that the origin of the greater acidity of I than III lies in the large increase in the electrostatic attraction between the $\mathrm{p}$ type lone pair developed on the anionic center $\left(\mathrm{C}^{\mathrm{l}}\right)$ and the cationic center $\left(\mathrm{C}^{4}\right)$ on going from $\mathbf{I}$ to $\mathbf{I}^{-}$compared to that from III to III $^{-}$

The energies $\left(\Delta E^{\circ}\right)$ of ionization are decomposed into charge-transfer $\left(\Delta E_{C \mathrm{~T}}\right)$ and non-charge-transfer $\left(\Delta E_{\mathrm{N} C \mathrm{~T}}\right)$ tenns $^{13}$ in Table 4 . First of all we note that the chargetransfer term is negative $\left(\Delta E_{C 1}<0\right)$ while the non-charge-transfer term is positive $\left(\Delta E_{\wedge C T}>0\right)$ and the overall ionization energies are positive $\left(\Delta E^{\circ}>0\right)$. This means that the anionic forms (e.g. $\mathbf{I}^{-}$) are more stabilized by charge transfer delocalization but are more destabilized by non-chargetransfer energies than the neutral forms (e.g. I). and the latter $\left(\Delta E_{\mathrm{N} C \mathrm{I}}\right)$ is numerically greater than the former $\left(\Delta E_{\mathrm{Cl}}\right)$. As we have discussed above in the structure section. the charge transfer stabilization in the anionic forms increases a great deal due to the two strong $\mathrm{n}_{C} \rightarrow \pi_{C=0}^{*}$ vicinal charge transfer interactions involving a relatively high energy $\mathrm{p}$ type lone pair on the anionic center. $\mathrm{C}^{l}$. However. this charge

Table 4. Decomposition of energies of ionization at the B3LYP/6$311++\mathrm{G}(3 \mathrm{df}, 2 p)$ level $)$ into charge-transter $\left(\Delta E_{C T}\right)$ and non-chargetransfer $\left(\Delta E_{\mathrm{N} C \mathrm{~T}}\right)$ temns (in kcal $\mathrm{mol}^{-1}$ )

\begin{tabular}{cccc}
\hline & $\Delta E^{\prime}$ & $\Delta E_{\mathrm{CT}}$ & $\Delta E_{\mathrm{XCT}}$ \\
\hline I & 336.6 & -235.4 & 572.0 \\
II & 338.3 & -270.5 & 608.8 \\
III & 339.7 & -293.6 & 633.3 \\
\hline IV & 334.0 & -269.3 & 603.3 \\
V & 338.0 & -299.6 & 637.6 \\
VI & 340.0 & -325.6 & 665.6 \\
\hline VII & 351.6 & -292.5 & 644.0 \\
VIII & 346.5 & -305.3 & 651.8 \\
IX & 346.1 & -238.2 & 625.7 \\
\hline
\end{tabular}


transfer stabilization is the lowest with $\mathbf{I}^{-}$since the $\pi_{C=0}^{*}$ level is elevated by lone pairs in the two ether oxygens. The $\mathrm{p}$ type lone pair on the anionic center $\mathrm{C}^{\mathrm{l}}$. however. causes enormous exclusion repulsion within the anionic forms. This is why there is large increase in destabilization represented by $\Delta E_{\text {Nic. }}$. which includes exclusion repulsion. electrostatic and steric interaction energies. ${ }^{13}$ This $\Delta E_{\mathrm{N} C \mathrm{~T}}(>0)$ term. being numerically greater than $\Delta E_{\mathrm{CT}}(<0)$. determines the overall ionization energy: $\Delta E^{\circ}(>0)$. We can now consider repulsive. destabilizing part and stabilizing, attractive part. which are comprised in $\Delta E_{\mathrm{NCT}}$ term. The strongest repulsion should be those between negative charges on $C^{l}$ and ether $\left(\mathrm{O}^{5}\right.$ or $\left.\mathrm{O}^{6}\right)$ (or methylene carbon) and carbonyl oxygens. The NPA charges on $\mathrm{C}^{l}, \mathrm{O}^{6}$ or methylene carbons are compared for I and III in Figure 5. We note that the negative charges on $\mathrm{C}^{3} \cdot \mathrm{O}^{6}$ and carbonyl oxygen increase as $\mathbf{I}$ is ionized to $\mathbf{I}^{-}$. which is as expected since there is an anionic center. a p-type lone pair. formed in $\mathbf{I}^{-}$. However the situation is reversed with III for which negative charges both on $\mathrm{C}^{\mathrm{l}}$ and methylene carbons decrease as $\mathrm{III}$ is ionized to $\mathrm{III}^{-}$albeit negative charges increase on carbonyl oxygens. The negative charge decrease on $\mathrm{C}^{\mathrm{l}}$ in $\mathrm{III}^{-}$is due to the two strong $\mathrm{n}_{\mathrm{C}} \rightarrow$ $\pi_{C=0}^{*}$ vicinal charge delocalizations in III $^{-}$. which is. as discussed above. much stronger than the corresponding interactions in $\mathbf{I}^{-},-\Delta E_{\mathrm{CT}}\left(\mathbf{I I I}^{-}\right)>-\Delta E_{\mathrm{CT}}\left(\mathbf{I}^{-}\right)$. Comparison of ionizations of $\mathbf{I} \rightarrow \mathbf{I}^{-}$with III $\rightarrow$ III $^{-}$. thus leads to a greater destabilization by repulsive interactions between greatly increased negative charges in $\mathrm{I}^{-}$than in $\mathrm{III}^{-}$where negative charge increase is smaller. If this destabilization were to prevail in the $\Delta E_{\text {NCT }}$ term. the acidity' of the Meldnum's acid. I. should have been lower than that of dimedone. III. i.e. . $\Delta G^{\circ}$ (I) $>\Delta G^{\circ}$ (III). This is not the case. however. as we know well the reverse holds. $\Delta G^{\circ}$ (I) $<\Delta G^{\circ}$ (III). We therefore should introduce and compare attractive. stabilizing interactions included within $\Delta E \mathrm{NCT}$ term. The stabilizing electrostatic interaction between $\mathrm{C}^{1}\left(\mathrm{q}_{1}<0\right)$ and $\mathrm{C}^{4}\left(\mathrm{q}_{4}>0\right)$ or between the groups $\left(\mathrm{C}^{+}+\mathrm{H}_{2}\right.$ or $\mathrm{H}$ and $\left.\mathrm{C}^{+}+\left(\mathrm{CH}_{3}\right)_{2}\right)$ increases substantially in the ionization of $\mathbf{I}\left(\rightarrow \mathbf{I}^{-}\right)$as shown in Table 1. This attractive interaction is absent in the ionization of III $\left(\rightarrow\right.$ III $\left.^{-}\right)$so that the $\Delta E_{\text {NicT term is much }}$ larger positive with III $\left(633.3 \mathrm{kcal} \mathrm{mol}^{-1}\right)$ than with I $(572.0$ $\mathrm{kcal} \mathrm{mol}^{-1}$ ). This greater repulsive $\Delta E \mathrm{NCT}$ term with III than I more than compensate for the larger charge transfer stabilization. $\Delta E_{\mathrm{CT}}(<0)$, with III $\left(-293.6 \mathrm{kcal} \mathrm{mol}^{-1}\right)$ than I $\left(-235.4 \mathrm{kcal} \mathrm{mol}^{-1}\right)$. In effect the stronger acidity of $\mathrm{I}$ than III $\left(\delta \Delta E^{0}=3.1 \mathrm{kcal} \mathrm{mol}^{-1}\right)^{-4} \mathrm{can}$ be attributed to the larger increase in the electrostatic stabilization accompanied with the ionization of $\mathbf{I}$ than that of $\mathbf{I I I}$

The same argument applies to the stronger acidity of $\mathbf{I}$ compared to its acyclic analogues. VII $\left(\delta \Delta E^{\circ}=14.9 \mathrm{kcal}\right.$ $\mathrm{mol}^{-1}$ ). In VII the strong cationic center $\mathrm{C}^{+}$is absent (and hence the strong $\mathrm{C}^{\mathrm{l}} \leftrightarrow \mathrm{C}^{4}$ attractive interaction is absent) and the increase in the stabilizing electrostatic interaction in the ionization of VII is so low that despite the larger increase in the charge-transfer stabilization $\left(\Delta E_{C \mathrm{C}}=-292.5\right.$ for VII $v$ $-235.4 \mathrm{kcal} \mathrm{mol}^{-1}$ for I) the acidity is much weaker than I

Among the three acyclic series. VII-IX. the increase in the
$\mathrm{n}_{\mathrm{C}} \rightarrow \pi_{C=0}^{*}$ vicinal charge transfer stabilization in the ionization. $\Delta E_{C \mathrm{CT}}$. is the greatest for VIII $(=-305.3 \mathrm{kcal}$ $\mathrm{mol}^{-1}$ ) and there is also a concomitant increase in the $\Delta E_{\mathrm{NCT}}$ $\left(=651.8 \mathrm{kcal} \mathrm{mol}^{-1}\right)$ term. Table 4 . This is again due to the lowest $\partial^{*} c=0$ level $(0.3375$ a.u. $)$ among the three anionic forms compared ( 0.3483 and 0.3625 a.u. for $\mathbf{V I I}^{-}$and $\mathbf{~ X}^{-}$. respectively). The stronger delocalization due to the $\mathrm{n}_{\mathrm{C}} \rightarrow$ $\pi_{C=0}^{*}$ interaction will result in a lower atomic charge on $\mathrm{C}^{l}$. which should lead to a lower attractive electrostatic interaction between $\mathrm{C}^{1}$ and other neighboring positive atomic centers within the Sickel type anion. VIII'- This causes to raise the $\Delta E_{\mathrm{N} C \mathrm{~T}}$ term. In the acyclic series there is no strong cationic center on $\mathrm{C}^{4}\left(\mathrm{R}_{2} \mathrm{C}^{++}(\mathrm{O}-)_{2}\right.$ where $\mathrm{R}=\mathrm{H}$ or $\left.\mathrm{CH}_{3}\right)$ so that the strong attractive electrostatic interaction between $\mathrm{C}^{3}$ and $\mathrm{C}^{4}$ is missing. Instead there are several weak attractive interactions between anionic centers. $\left(\mathrm{C}^{]}\right.$. ether oxygens and carbonyl oxygens) and neighboring hydrogens within the Sickel shaped anions. VII $^{-}$. VIII' ${ }^{-}$and $\mathbf{~ I X}^{-}$. There is a general trend that an increased $n_{C} \rightarrow \pi_{C=0}^{*}$ vicinal charge transfer stabilizations $\left(\delta \Delta E_{C \mathrm{~T}}<0\right)$ in the anionic form leads to a decrease in the major electrostatic stabilization involving anionic center at $\mathrm{C}^{1}\left(\mathrm{C}^{l} \leftrightarrow \mathrm{C}^{-}\right)$due to a decrease in the negative charge on $\mathrm{C}^{l}$. The decrease in the electrostatic stabilization invariably raises the $\Delta E_{\mathrm{N} C \mathrm{~T}}$ term. $\left(\delta \Delta E_{\mathrm{NCT}}>0\right)$. This is why there is an inverse relationship between $\delta \Delta E \mathrm{CT}$ and $\delta \Delta E_{\mathrm{K} C \mathrm{~T}}$ in the comparison of any two compounds. Table 4. Since the overlaps between the p type lone pair on the anionic center $C^{l}$ and the two carbonyl $\pi^{*}$ orbitals are similar and hence the term does not vary much in all the compounds. the $\pi_{C^{\prime}=0}^{*}$ level (and hence $\Delta \varepsilon=\varepsilon_{\pi^{*}}-\varepsilon_{\mathfrak{n}}$ ) determines the $\mathrm{n}_{\mathrm{C}} \rightarrow \pi_{C=0}^{*}$ delocalization stabilization. $\Delta E^{O}{ }_{n \rightarrow \pi^{*}}$ in eq. 3. The amount of negative charge on the anionic center $\mathrm{C}^{\mathrm{l}}$ has a major effect on the $\Delta E_{\mathrm{N} C \mathrm{~T}}$ term since it is involved in the predominant electrostatic repulsions

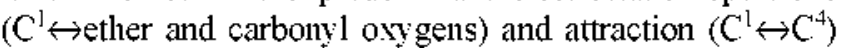
in the neutral as well as in the anionic molecules (vide supra).

Surprisingly, the acidity of 1.3-dioxane-4.6-dione. IV. is stronger than that of Meldrum's acid. I. by $2.1 \mathrm{kcal} \mathrm{mol}^{-1}$ $\left(\delta \Delta G^{\circ}=-2.1 \mathrm{kcal} \mathrm{mol}^{-1}\right)$. The component analy'sis suggested that the lower ionization energy of IV than I $\left(\delta \Delta E^{\wedge}=-2.6\right.$ kcal $\mathrm{mol}^{-1}$ ) is due to a smaller increase in $\Delta E_{\mathrm{NCT}}$ term $\left(\delta \Delta E_{\mathrm{N} C \mathrm{~T}}=+31.3 \mathrm{kcal} \mathrm{mol}^{-1}\right)$ than the greater charge transfer stabilization $\left(\delta \Delta E_{C \mathrm{~T}}=-33.9 \mathrm{kcal} \mathrm{mol}^{-1}\right)$. This may result from a greater electrostatic stabilization due to the larger increase in positive charge on $\mathrm{C}^{4}$ in $\mathbf{I V}^{-}$(from +0.267 to +0.280 ) than the corresponding charge on $\mathrm{C}^{+}$in $\mathbf{I}^{-}$(from 0.579 to 0.574 ) with similar negative charge on the opposite end of $\mathrm{C}^{1}\left[-0.610(\mathbf{I}) \rightarrow-0.628\left(\mathbf{I}^{-}\right) \vee s-0.612(\mathbf{I V}) \rightarrow\right.$ $\left.-0.631\left(\mathbf{I V}^{-}\right)\right]$. The greater acidity of $\mathbf{I V}$ than $\mathbf{I}$ predicted in the present work. however. cannot be verified in the absence of any experimental $\mathrm{p} K_{\mathrm{a}}$ measurement for $\mathbf{I V}$.

\section{Summary}

Our results of DFT studies at the B3LYP/6-311+G(3df .2p) level predict a boat conformation for Meldrum's acid (I) 
and gradual changes to a twisted chair (II) and to a chair (III) as the methylene group is substituted successively for the ether oxygens. All the cyclic anionic forms $\left(\mathbf{I}^{-} \rightarrow \mathrm{VI}^{-}\right)$ have half-chair forms due to planar delocalized structure $(-\mathrm{C}(=\mathrm{O})=\mathrm{Cll}=\mathrm{C}(=\mathrm{O})-\mathrm{f}$ involving the anionic carbon center $\left(\mathrm{C}^{\prime}\right)$ and the two carbonyl groups. The major factor controlling the conformations in the cyclic compounds is the 1.4-electrostatic interaction, which is attractive in the boat form (I) whereas it is repulsive in the chair form (III). The dipole-dipole interaction theory cannot be invoked for rationalization of the higher acidity of Meldrum's acid (I) than dimedone (III). The driving forces in the ionization of Meldrum's acid are the strong chargetransfer delocalization $\left(\Delta E_{(\mathrm{T}}<0\right)$ and I.4-electrostatic attraction in the ionized form $\left(\mathrm{I}^{-}\right)$, both of which involve a $\mathrm{p}$ type lone pair on the anionic center, $\mathrm{C}^{l}$. The lower acidities of acyclic series (VII-IX) than the corresponding cyclic series (I-VI) are mainly due to absence of the strong cationic center, $\mathrm{C}^{4}$, in the latter.

Acknowledgement. This work was supported by grant No. R0l-1999-00047 from the Basic Research Programs of the Korea Science and Engineering Foundation.

\section{References}

1. Meldrum. A. N. J. (hem. Soc. 19118. 93. 598.

2. (a) I'ihlajia. K.: Seilo. M. Actat ('tr'm. Scont. 1968. 22.3053. (b) Pihlaja. K.: Scilo. M. Acter chen. Scond. 1969. 23. 3003.

3. Davidson. D.: Bernhard. S. A.J. Am. Chem. Soc 1948, 70, 3426.

4. Pthuger. C. Г..: Boxle. P. D. J. Chem. Soc. Perkin Trems. 21985. 1547 .

5. Arne1l. E. M.: Maroldo. S. L.: Shilling. S. L.: Harrelson. J. A. .J. in. (hem. Soc 1984. 106.6759.

6. Arnett. E. M.: Harrelson. I. A. J. Am. Chem. Soc. 1987. 109. 809.

7. Wing. X.: llouk. K. N. J. Am. Chem. Soc, 1988. /10. 1870.

8. Wiberg. K. B,: l.aidig. K, Г. J. Am. Chem. Soc. 1988. /10, 1872.

9. Bzyu. K.: Mo. Y.: (jao. I. J. Am. Chen. Soc. 2001. 123. 3974.

10. Frisch. M. J.: Irucks. G. W.: Schlegel. H. B.: Scuseria. G. E.: Robb. M. A.: Cheeseman. J. R.: Lahrcewski. V. G.: Montgomery. J. A.. JI:. Stratmatıts. R. E.: Burant. J. C.: Dapprich. S.: Millam. J. M.: Danicls, A. D.: Kudin. K. N.: Strain. M, C.: Farkas. O.: Tomasi, J.: Barone. V.: Cossi, M.: Cammi, R.: Mınnucei, B.: pomelli. C... Adamo. C... Clithord. S.: Ochterski. J.: Peterswon. (j. A.: Ayala. I'. Y.: Cui. Q.: Morokuma. K.: Malich. D. K.: Rabuch. A. D.: Raghawachari. K.: Foresman. I. B.: Cioslowshi. J.: Ortic. J. V:: Stetanov. B. B.: Lit.. G.: Liashenko. A.: Piskorz. P.: Komaromi.
I.: Gomperts. R.: Martin. R. L.: Fox. D. J.: Keilh. I.: Al-Lahtam. M. A.: Potı. C. Y.: Vanayakkara. A.: Gonzalez. C.: Challacombc. M.: Gill. P. M. W.: Johnson. B.: Chon. W.: Wong. M. W.: Andres. J. J ..: Gionzales. C.: I Jaad-Giordon. M.: Replogle. Г., S.: Pople. J. A. Gaissian 28. Rewision 1.6: (jaussian. Inc.: Pittshurgh. PA. 1998.

11. (a) Jehre. W. J.: Radom. I..: Schleyer, P. v. R.: Pople, I. A. Ib Intio Holecular Orbital Theor: Wiley: New York. 1986. (b) Jensen. F. Introduction to computational (hemistry: Wiley: Chichester: 1999.

12. (a) Curtiss. I. A.: Raghavachari. K.: Redfern. P. C.: Redfern. P. C.: Rassolov, V.: Pople. I. A. J. Chem. Phws. 1998, 109. 7764. (b) Curtiss. I. A.: Redlern. P. C.: Raghavachari. K.: Rassolow. V.: l'ople. J. A. J. Chem. Phs 1999. 1/0. 4703. (c) Baboul. A. G.: Curtiss. L. A.: Redfers. P. C.: Raghavachari. K. . Chem. Hhy. 1999. /10. 7650. (d) Curtiss. L. A.: Raghavachari. K. Theor: Chent. Ace, 2002. 108.61.

13. (a) Reed. A. J.: Curtiss. I. A.: Weinhold I: Chem. Res 1988, 88, 899. (b) Reed. A. I:.: Weinstock, R. B.: Weinhold, I: J. Chem. Phys. 1985. 83. 735. (c) Brunck. l. K.: Weinhold. F. f. An. (hem. Soc. 1979. 101. 1700. (d) Lec. l. Int. Rev. Ihys. (hem. In press. (c) Recd. A. E.: Woinstock. R. B.: Woinhold. F. J. Chem. Phys. 1985. 83. 735. (f) Reed. A. F.: Weinhold. F. J. Chem. Phns. 1983. 78. 4066 .

14. L iptak. M. D.: (jouss. K. C..: Seybold, P. G.: Feldgus, S.: Shields. (i. C... Am. Chem. Soc. 20112. 124.6421.

15. Klimovitskij. E. N.: Yuldashova. L. K.: Arbuzov. B. A. Izv. Ahad. tinte SSSR, Ser Khim. 1973. 1577

16. (a) Ayras. P.: Partanen. A. Fimm. Chem. Lem. 1976. I l0. (b) Ayras. P. Acta Chem. Scond. 1976. B37. 957.

17. Ipiotis. N. D.: Cheny. W. R.: Shaik. S.: Yates. R.: Bermardi. I: Strutural Theony of Omanic (hemisty: Springer-Verlag: Berlin. 1977.

18. Perez. G. V.: Psrez. A. L. f. Chem. Edu. 2000. 77. 910.

19. (a)Bordwill. F. G, Plre Appl. Chem. 1977. 49, 963, (b) Franseck. J. D.: Houk. K. N.: Briggs. I. M.: Jorgensen, W. 1., J. Am. Chem. Soc. 1994. /16. 10630. (c) Wiberg. K. B.: Wong. M. W. J. Im. ('he'm. Soc. 1993. //5. 1078.

20. (a) Li. H. G.: Kim. C. K.: Lee. B.-S.: Kim. C. K.: Rlıe. S. K.: Lee. I. J. An. Chem. Soc 200I. 123. 2326. (b) Kim. C. K.: Li. H. G.: I.2. B.-S: Kim, C.. K.: I.ec. II. W.: l.ce, I, J. Org. Chem, $2002,67$.

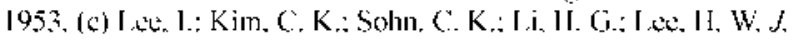
Phs (hem. A 2002. 106. $108 \mathrm{l}$.

21. (a) l'etersson. G. A.: Malik. D. K.: Wilson. W. G.: Ochterski. I. W.: Montgomery. J. A.. Ir.: Frisch. W. J. I. Chem. Phs. 1998. 109. 10570. (b) Lec. I.: Li. H. G.: Kim. C. K.: Les. B.-S.: Kim. C. K.: I ces. II. W. J. Org. Chem.. Submitted.

22. Karty, J. M.: Janeway. (1. A.: Brauman, I. I. J. Am. Chem. Soc. 20102. 12+. 5213 .

23. Raghavachari. K.: Whiteside. R. A.: Pople. I. A.: Schleyer. I? v. R. J.1m. (them. Soc 1981. 103. 5649. Ihis is $\delta \Delta \mathrm{E}^{\circ}$. which is the samc as $\delta \Delta G^{\circ}$ at the B3LYP6-311-+G(3dt.2p) level. The $\delta \Delta G^{*}$ value at the $\left(\mathrm{i},(+)(\mathrm{MP} 2)\right.$ level is $4.1 \mathrm{kcl} \mathrm{mol}^{-1}$. 